\title{
Detecting Mobile User Position Without GPS on Android OS
}

\author{
$\underline{\text { doi:10.3991/ijim.v4i3.1269 }}$
}

\author{
B.Dorjnamjirmaa, D.Battulga, J.Uitumen and Sh.Sodbileg \\ National University of Mongolia, Ulaanbaatar, Mongolia
}

\begin{abstract}
Cell systems divide their service territories into many little "six equal part crystal" cell-shaped parts. This offers a great opportunity to increase a number of consumers because of used frequency repeatedly.

Cell system divides its whole serving region into six equal cell parts and establishes one base station in each cell. The antenna of the base station is located on top of high buildings within each cell with most stations using micro strength signals. These stations have their own unique numeration and specific location. This research aims to identify the specific location of cellar telephones to determine the geographic position by triangulating signal quality from three base stations.
\end{abstract}

Index Terms - android operation system, position detection, Geographic Positioning Service.

\section{INTRODUCTION}

\section{A. Identifying quality of signal received from multiple} stations

In cell phones employing many different operating systems, the signal quality they receive from multiple stations and data from respective stations are not directly reflected in their program development base. Therefore, in order to obtain the above mentioned data, we need to study the lower level codes of an operating system. This process will be performed using an Android system which is produced for pocket tools by Google. After enhancing these tools to improve signal quality and data transmission simultaneously from multiple stations, we will identify the location of the cell phone which has the modified operating system installed. The following is an example of the signal processing module of the Android operating system:

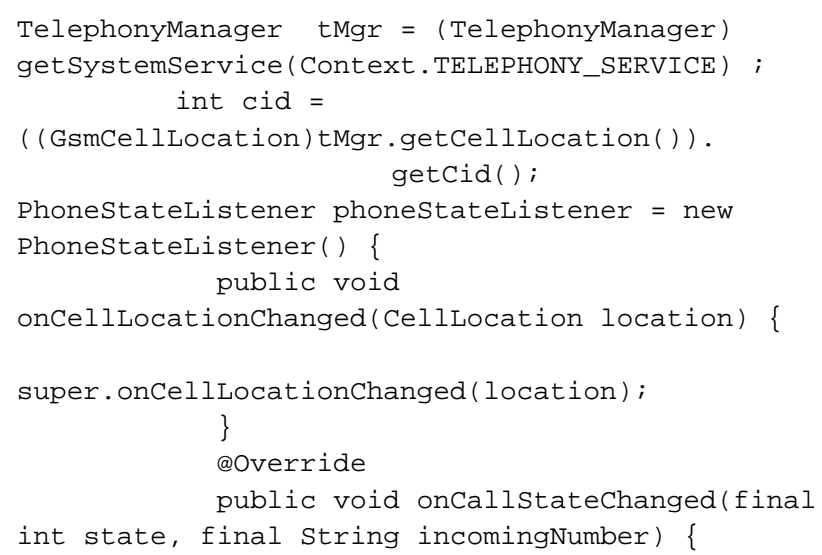

super. oncallstatechanged(state, incomingNumber):

\}

@override

public void

onsignalstrengthchanged(int asu) \{

$$
\text { si_asu }=\text { asu; }
$$

\}

si_dBm $=-113+2$ *asu;

tMgr. listen (phonestateListener, PhonestateListener . LISTEN_CELL_LOCATION |

PhonestateListener.LISTEN_SIGNAL_STRENGTH |

PhoneStateListener.LISTEN_CALL_STATE ）；

mcc $=$ tMgr.getSimCountryIso( $) ;$

$\mathrm{mnc}=\mathrm{tMgr}$.getNetworkoperator () ;

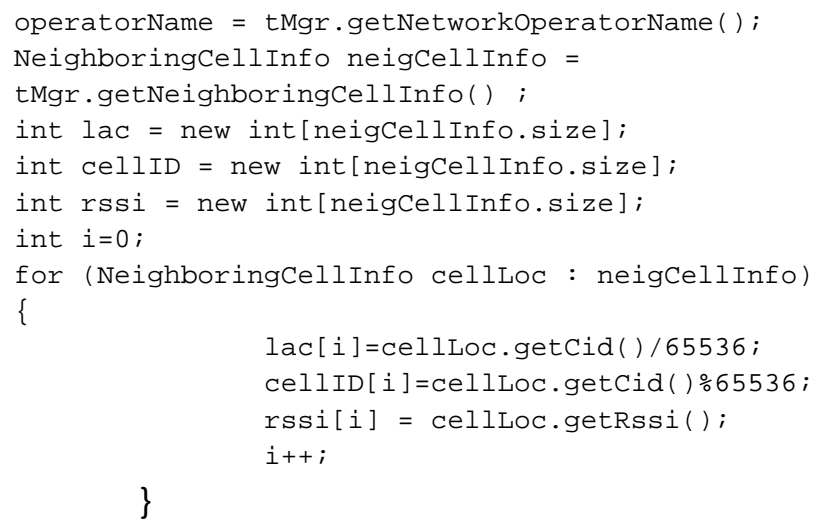

\section{IDENTIFYING THE LOCATION}

Cellular telephones require highly precise location identification, based on very specific parameters. In order obtain our measurements, we must receive at least three signals sent by different stations. Location identification methods vary from each other, based on the signal quality received by the cellular telephone. Preciseness of location identification is usually in the range of 50 meters up to several tens of meters depending on which kind of method is used. We used the E-OTD method to identify location. In the cellular phone based methods, the mobile station determines its own location and performs Observed Time Difference (OTD). Consequently, the mobile station must have additional data, including the information required to coordinate Base Transceiver Station (BTS), Real Time Difference (RTD) values, and the signal quality received from the BTS. 


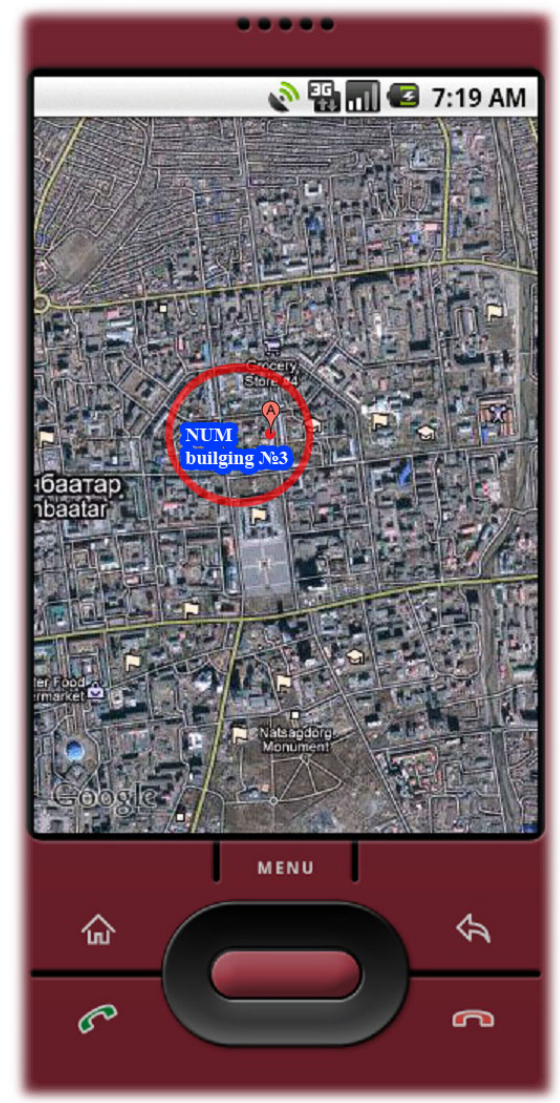

Figure 1. Determining user position in the mobile device display

\section{CONCLUSION}

Detecting cell phone location using Global System for Mobile communications (GSM) without using Global Positioning Service (GPS) is possible by processing calculations based on the received signal quality because each cell phone has its own unrepeated unique number. Therefore, by triangulating the reception of 3 or more BTS, the geographic position can be determined with a high degree of accuracy. In order to recognize the quality of signals received from more than one $\mathrm{BS}$, we studied the signal processing module of the Android operation system which is produced for pocket tools by Google. Then we used the quality of signals received at the cell phone to determine its precise location using E-OTD.

\section{ACKNOWLEDGMENT}

We wish to recognize the support for this project by the Asia Research Center

\section{REFERENCES}

[1] Vijay, G., Wireless communications and networking (2007)

[2] Lawrence David, B., Introduction to Mobile telephone systems: 1G, 2G, 2.5G and 3G Wireless Technologies and services (2004) 347, 354

[3] Molisch ,F., Wireless Communications (2005)

[4] Ng, K., Chan. H.W., Enhanced Distance-Based Location Management of Mobile Communication Systems Using a Cell Coordinates Approach (2005)

[5] Nabil NASSER (2008), Automatic Location Information System for Mobile phone

[6] Dan Kenneth Johnson and Jurgen Olavesen,

[7] Estimated Accuracy of location in mobile networks using E-OTD

\section{AUTHORS}

Sh. Sodbileg is with the Mobile and Embedded Technology Research Center, National University of Mongolia (e-mail: sdblg@ num.edu.mn). He received his PhD degree from Kyungpook National University, Korea.

D. Battulga is now with the School of Information Technology, National University of Mongolia (e-mail: battulgad@num.edu.mn). He received his engineering masters degree from the National University of Mongolia.

B. Dorjnamjirmaa is with the Department of Computer Science, National University of Mongolia (e-mail: b.dorjoo@num.edu.mn).

This work was supported in part by ARC.

Manuscript submitted on March $16^{\text {th }}, 2010$. Published as resubmitted by the authors on June $29^{\text {th }}, 2010$. 